
RU Рецепция французского физиологического очерка в России
(на примере «типов» рабочего и старой девы)

\author{
Петрова Р. Ю.
}

Аннотация. В статье рассматривается вопрос рецепции французского физиологического очерка в России (на примере двух представленных в очерках «типов»). Цель исследования - на основе выделенных черт сходства и различия французских и русских текстов охарактеризовать физиологический очерк как жанр европейской художественной литературы, обнаруживающий наднациональные черты. Научная новизна: в ходе сопоставительного анализа нескольких французских и русских физиологических очерков было установлено, что русские очерки тяготеют к индивидуализации изображаемого героя, тогда как во французском тексте эта черта отсутствует. Результаты научного исследования: в процессе исследования обнаружено, что как для французских, так и для русских очерков характерно детальное изображение общественных «типов»; на основании выявленного тяготения к индивидуализации «типа» можно утверждать о наличии в русских очерках параллели к апологии «маленького человека».

\title{
Reception of the French Physiological Essay in Russia (by the Example of Worker and Spinster Images)
}

\section{Petrova R. Y.}

\begin{abstract}
The article analyses reception of the French physiological essay in Russia by the example of worker and spinster images. The research objectives are as follows: to identify universal and nationally specific features of the French and Russian essays, to describe the physiological essay as a universal genre of the European fiction. Scientific novelty: relying on a comparative analysis of the French and Russian physiological essays, the researcher concludes that the Russian authors, contrary to their French counterparts, tend to individualize their characters. The research findings are as follows: it is proved that both the French and Russian essays contain detailed description of social types; the identified tendency of characters' individualization testifies to existence of the "little man" motive in the Russian essayistics.
\end{abstract}

\section{Введение}

Актуальность темы статьи связана с современным научным интересом к беллетристике как роду литературы и с очевидной потребностью в расширении и углублении знаний о жанре физиологического очерка.

Для достижения нашей цели было необходимо решить следующие задачи: определить основные характеристики физиологического очерка как жанра, провести сравнительный анализ выбранных пар очерков и выявить черты сходства и различия.

В своей работе мы использовали такие общенаучные методы, как анализ и обобщение, а также сравнительно-типологический метод анализа художественного текста.

Теоретическую базу исследования составляют литературоведческие работы, предметом которых является литература 30-40-х гг. XIX в. России и Европы. Так, в частности, В. Г. Белинский даёт характеристику автора физиологического очерка как умелого дагерротиписта [2]. «Двуединый генезис» [4] русских физиологий неоднократно упоминают В. И. Кулешов [10], Ю. В. Манн [11], А. Г. Цейтлин [12]. Разнообразные виды рецепции европейской литературы в русской литературе были замечены и описаны В. Э. Вацуро [3].

Практическая значимость данной статьи заключается в возможности использования ее результатов в преподавании дисциплин литературоведческого профиля (история литературы, компаративистика).

\section{Физиологический очерк как жанр}

Жанр физиологического очерка, как известно, пользовался исключительной популярностью в 40-х гг. XIX в. во Франции и России. Главной установкой этого жанра было подробное изображение современного общества, 
детальное описание быта и нравов. Авторы физиологических очерков показывали жизнь представителей разных классов (в основном низших), давая своим «типам» профессионально-бытовые характеристики [13].

Во Франции физиологические очерки первоначально появляются на страницах журналов (“Сaricature” (1830), “Charivari” (1832) и др.), затем издаются в составе различных сборников (“Les français peints par eux-mêmes”, 1840-1842; “Le livre des cent et un”, 1831-1834; “Le diable à Paris”, 1845-1846 и др.). В жанре «физиологий» писали как крупнейшие писатели того времени (Бальзак, Жорж Санд, Ж. Жанен, А. Карр, Ф. Сулье, Поль де Кок), так и те, чьи имена сейчас известны только узкому кругу исследователей (А. Секонд, П. Дюваль и др.).

История русского физиологического очерка, ставшего одним из ведущих жанров «натуральной школы», начинается альманахом А. П. Башуцкого «Наши, списанные с натуры русскими» (1841-1842 гг.) [4; 5]. 3а ним последовали сборники «Очерки московской жизни» (1842) П. Вистенгофа, «Очерки русских нравов, или Лицевая сторона и изнанка рода человеческого» (1843) Ф. В. Булгарина, альманахи Н. Е. Некрасова «Физиология Петербурга» (1845), «Петербургский сборник» (1846), «1-е апреля» (1846). Среди авторов русских физиологических очерков - Д. В. Григорович, И. И. Панаев, В. Р. Зотов, В. И. Даль, П. В. Ефебовский, Я. П. Бутков, А. Я. Кульчицкий. Как не раз отмечалось исследователями [10, с. 13; 11, с. 243; 12, с. 12], для русских «физиологий» характерен «двуединый генезис» [4]: соотносимые с отечественной нравописательной традицией конца XVIII начала XIX в. (этнографические «очерки нравов» К. Н. Батюшкова («Прогулка по Москве», 1811-1812 гг.), В. Ф. Одоевского («Бал», 1833 г.), Н. А. Полевого («Новый живописец общества и литературы», 1832 г.)), они в то же время являли собой результат воздействия французского нравоописательного направления.

Структура физиологического очерка отличается от таковой других разновидностей литературной публицистики. Для него характерно не только точное воспроизведение фактов, но и попытки предоставить статистически верные сведения об описываемом «типе». В большинстве очерков сюжет как таковой обычно отсутствует, поскольку основной целью очерка является не повествование о каком-либо событии, но описание некоего явления, подчиненное задаче изображения соответствующего социального «типа». Основными характеристиками героев становятся их воспитание, образование, жизненные условия. Особенное внимание уделяется не только самому «типу», но и характеристике среды, в которой он проживает. Как отмечал в свое время В. Г. Белинский, у автора физиологического очерка «нет таланта чистого творчества... он не может создавать характеров, ставить их в такие отношения между собой, из которых образуются сами собой романы и повести. Он может изображать действительность, виденную или изученную им, или, если угодно, творить, но из готового, данного действительностью материала» [2, с. 345].

\section{Сравнительный анализ французских и русских очерков}

Насколько нам известно, последовательного сравнения репрезентации «типов» во французском и русском физиологических очерках еще не предпринималось (редкое исключение здесь - недавняя статья А. Ю. Каревой, где сравниваются два очерка, в центре которых - «тип» писателя [8]). Между тем, как представляется, соответствующее исследование позволило бы в значительной мере расширить и углубить существующие представления о характере влияния французской традиции «физиологий» на русскую словесность 30-40-х годов XIX века. Поставив перед собой данную цель, мы выбрали для сопоставительного анализа французские и русские «физиологии», описывающие два «типа»: рабочий и старая дева.

При первом взгляде обращает на себя внимание прежде всего определенная идеализация образа рабочего как во французском, так и в русском вариантах этого «типа». Так, по описанию М. Бриссэ (Mathurin-Joseph Brisset) (очерк “L’Ouvrier de Paris”, 1842), рабочий - труженик, он религиозен, безропотно воспринимает выпавшие на его долю тяготы жизни; его имя столь же почетно, как и имя солдата. Он весьма сметлив: «Разговаривая с ним, изумляешься, как легко он понимает все темы, которые более или менее касаются его состояния. Если вы выказываете сомнение, что он понял вашу речь, сразу на помощь будет призван рисунок, и четырьмяпятью штрихами мела или угля он набросает вам на стене разные предметы, о которых вы говорили - и даже лучше и яснее, чем вы сами пытались объяснить» (здесь и далее перевод автора статьи. - Р. П.) [14]. Отметим, что данная характеристика схожа с той, которую дает гамену (другой популярный «народный тип») Ж. Жанен в своем очерке о парижском гамене: «...урок начался, учитель приступил к объяснению; но гамен уже все понял. Он обладает самым живым, самым быстрым и самым чистосердечным разумом в мире. Это дух, который постоянно движется вперед, чистый и быстрый, как молния. Ничто его не удивляет: он учится так быстро, что кажется, будто он не узнает, а вспоминает» [15].

Эта идеализация видна и в описании отношения рабочего к своей семье. После смерти отца он становится опорой семьи - заботится о своей слепой матери, всю неделю трудолюбиво работая, а воскресенье посвящая ей (гуляя по лесам и полям, выслушивая ее наставления). Он - опекун и ментор своей младшей сестры (которую Бриссэ называет «единственным наследством, оставленным ему родителями, вместе с примером их благочестивой и честной жизни» [14]). Рабочий изменяет свой образ жизни: раньше он гулял с девушками, теперь с матерью; теперь он, чтобы служить примером сестре, «порученному ему сокровищу» [Ibidem], полностью поменял свое поведение: он религиозен более, чем кто-нибудь (что Бриссэ объясняет следующим образом: «Христос оправдал работу... Бог сказал: “работай, чтобы жить на Земле!”. Христос сказал: “Работай, чтобы жить со мной на небе”. Кто более, чем рабочий, повинуется этому повелению?» [Ibidem]). 
Вскоре рабочий женится, и в «поле идеализации» оказываются вовлеченными еще два персонажа из его окружения: жена и ребенок. Новобрачная, воцарившись в «скромном жилище» [Ibidem] рабочего, оказывает на все «счастливое, благотворное и священное влияние» [Ibidem]. Она «освещает его жизнь» [Ibidem], является «олицетворением поэзии, любви, религии» [Ibidem]. Более того, она становится музой: «..ободрение, вспышка вдохновения, которую ждал неизвестный дух, чтобы заставить появиться изобретение, которое должно будет обессмертить имя своего изобретателя в летописях индустрии»; жена - «нежность, радость, терпение, которых ему прежде недоставало» [Ibidem]. Рождение ребенка описано самым душещипательным образом: у его колыбели рабочий «превращается в нежную, внимательную, услужливую женщину... вполголоса напевает колыбельные, прерываясь, чтобы взглянуть и еще раз облобызать белый и чистый лоб ангела, посланного ему небом» [Ibidem].

Обращают на себя внимание характерные образы и сравнения, используемые автором в этом очерке: «сокровище» (о сестре рабочего), «ангел» (о ребенке), «добрый дух» (молодая жена), слепая беспомощная мать, благородные бедняки, не поддающиеся унынию (как, например, молодая жена, которая напевает во время домашних хлопот, одновременно стараясь расслышать удары молота своего мужа).

Картина жизни водовоза, представленная А. Башуцким в одноименном очерке (1841), более гнетущая. Например, впервые повествователь сталкивается с водовозом через час после того, как тот получил травму, от которой через несколько дней скончается. Интересно, что рассказчик сначала не видит, а слышит рабочего: «...с первого шага меня поразили болезненные вздохи, раздававшиеся сверху» [1, с. 5]. В очерке описаны некоторые черты внешнего облика водовоза: «худенький, светло-русый, лет тридцати»; «кроткое, тоскливомиловидное лицо» [Там же]. Примечательно, что зовут героя Пантелеймоном - это заставляет вспомнить о великомученике Пантелеимоне, покровителе больных. Возможно, что рассказчик упоминает имя героя для того, чтобы сделать его образ более выпуклым. Вместе с тем отметим очевидную параллель между судьбами великомученика Пантелеимона и героя Башуцкого: оба были замучены (но святой был казнен по приказу императора Максимиана, а водовоз замучен своею «жизненной средой»: он «убился», поднимаясь по крутой лестнице с тяжелым грузом). Пантелеймон умирает в душном темном подвале Петербурга - это, в свою очередь, напоминает темницы, куда были заключены многие христиане в начале первого тысячелетия нашей эры.

Бриссэ, в отличие от Башуцкого, наделяет своего героя именем только один раз за весь очерк. Описывая, как рабочий возвращается с военной службы, автор цитирует народную песенку («Возвращайся в свою страну, / Возвращайся, Жан из Парижа!»), затем в первый и единственный раз называя героя очерка «Жаном», а не просто «рабочим». Здесь кажется возможным утверждать, что благодаря имени водовоза и, следовательно, определенной «индивидуализации» типа текст Башуцкого (в отличие от французского очерка) провоцирует иную, более «личную», читательскую реакцию.

Семейная жизнь водовоза практически не описана - упоминается только, что он женат на «Аксинье Чубаровой... красивая баба, что кровь с молоком, и разумница» [Там же, с. 11], что он, видимо, очень к ней привязан («не расстался бы он с нею ни за что и на день, да худые в нашей стороне настали времена» [Там же]) и что у них трое детей. Пантелеймон успел прожить и проработать в Петербурге около восьми месяцев, все заработанные деньги отправляя семье.

Упоминание имени («Аксинья», «Оксюша», «Оксюта» [Там же, с. 12]) жены водовоза - еще один отсутствующий у Бриссэ момент индивидуализации, благодаря которому реакция читателя снова меняется, становясь более эмоционально окрашенной. При сравнении семейной жизни рабочего во французском и русском текстах вырисовывается следующее соотношение: у французского автора - развернутое, но обобщенно-абстрактное, условночувствительное описание «типа», в то время как у А. Башуцкого наблюдаются попытки некоей «индивидуализации» «типажа» (фоном которому, впрочем, служит такое же схематично-обобщенное изображение водовоза).

Водовоз богобоязнен, смиренен, терпеливо переносит выпавшие на его долю страдания; обладает, повидимому, как и любой представитель своей профессии, «значительным невещественным капиталом терпения, аккуратности, добронравия и честности» [Там же, с. 19]; очень трудолюбив (работает с «шести утра до ночи» [Там же, с. 16]). Тем сильнее становится контраст между нарисованным светлыми красками образом рабочего и его жизнью. Действительность предлагает рабочему тяжелый труд, бедность («бедное хозяйство» [14]), отсутствие государственной поддержки («Где же эта организация рабочих профессий, это представительство от лица их нужд, их страданий?» [lbidem]; «Водовозы не имеют никакого официального состава, не представляют отдельной общины или цеха, не состоят в чьем-либо особом заведывании» [1, с. 15]), равнодушное отношение общества вообще и богатых людей в частности (Башуцкий так описывает отказ зажиточного человека на предложение облагодетельствовать кого-нибудь из водовозов: «...вы торопитесь на вечер, где должны проиграть в экарте, в палки или в шорт-уист 3000 р., а жена ваша должна гордо показать головной убор и бархатную мантилью, выписанные ею из очаровательного Парижа за такую сумму, которой было бы достаточно составить на три месяца счастье всех петербургских водовозов и их семейств!» [Там же, с. 21]), условия жизни (либо сложные, как у рабочего, либо невыносимые, как у водовоза), раннюю старость (или смерть, постигшая Пантелеймона).

Аналогичный прием контрастного соположения героя и окружающей среды был использован и в очерке М. Бриссэ, описывающего пороки общества, на фоне которых образ рабочего-труженика приобретает дополнительный позитивный (точнее - идеализирующий) акцент: «Как бы то ни было, человек, который работает в Париже, который ведет жизнь сосредоточенную, полную труда, размеренную, среди стольких увеселений и развлечений; в центре стольких несложных работ, заставляющих деградировать или запрещенных законом; он совершает храбрый, добродетельный и требующий сил поступок; его имя так же честно, как имя 
солдата: и, как артист, которому необходимо изобразить солдата, не выбирает в качестве образца ни труса, поворачивающегося спиной к врагу, ни дезертира, бросающего флаг, писатель, чтобы изобразить рабочего, не заставит позировать себе пьяницу или дебошира!» [14].

Говоря о сходстве приемов изображения персонажей французским и русским физиологами, обратим внимание на одну любопытную деталь. В очерке Башуцкого есть эпизод - рассказ о судьбе лошади водовоза, сюжетно перекликающийся с романом одного из известнейших французских очеркистов, Ж. Жанена, «Мертвый осёл и гильотинированная женщина» (“L’Âne mort et la femme guillotinée”, 1842). Как повествует Башуцкий, какое-то время на этой лошади ездила девушка, которую автор описывает, применяя синекдоху: «...два плутовские глаза... в прелестной головке... две полненькие, стройные ножки, пылко и беспутно пробежавшие жизнь, данную для лучшей цели» [1, с. 22]. Потом «этих ножек не стало» [Там же], а лошадь, переходя от хозяина к хозяину, оказалась наконец у татарина (планировавшего отправить животное на живодерню), откуда ее выкупил водовоз. Мотив быстрого падения красивой девушки и параллельная с этим гибель животного, на котором она ездила, - основное сюжетообразующее средство романа «Мертвый осёл».

При сопоставительном рассмотрении очерков «Старая дева» (“La vieille fille”, 1840) Мари Д’Эспийи (Маrie d'Espilly) и «Барышня» (1842), опубликованного за подписью «Княжна -а», прежде всего бросается в глаза разница в строении, объеме и стиле. Французский очерк четко делится на части: дидактически окрашенное вступление (в котором автор порицает общественные нравы и объясняет причину увеличения количества старых дев), основная часть (подробное описание каждой стадии развития старой девы и краткая характеристика разных типов старых дев), заключение. Русский очерк более краток, менее претендует на «научность» описания (единственная попытка такового обнаруживается в первых абзацах, где вкратце охарактеризован тип «старой девы») и в целом представляет собой сентиментально окрашенное изображение жизни барышни (подтипа «старой девы», согласно автору зарисовки).

Говоря же о чертах сходства указанных текстов, отметим очевидное соответствие «типических характеристик» старой девы, которая религиозна, суеверна, а также не любит молоденьких девушек («ненавидит молоденьких особливо хорошеньких девиц» [9, с. 33]; «терзаемая завистью, как самая законченная кокетка, Калигула в юбке, страдающая от невозможности разом опорочить, обезобразить, состарить всех женщин, которые предстают перед ней молодыми, красивыми, умными, любимыми... Девушки... ее коварные, а то и клеветнические речи безжалостно выставят напоказ малейшие ваши недостатки (перед возлюбленным. - Р. П.)» [6, с. 509]), питает слабость к животным («любит кошек, собак, птиц» [9, с. 33]; «взгляните на нее утром, когда, закончив туалет своего кота, она занимается своим собственным» [6, с. 509]) и любит романы («Она увлекается сентиментальной литературой и потому на ночь должна обязательно проглотить какой-нибудь роман» [Там же, с. 508]; «романы любит она страстно читать про себя» [9, с. 35]). Оба автора подчеркивают далее возможные «вариации» типажа; старая дева может быть самой разной: ученой («обогащают своими творениями музеи живописи и скульптуры, ставят свое имя рядом с именами редакторов ваших лучших научных и литературных журналов» [6, с. 505]; «старая девушка, не видя цели в жизни своей, предалась учености; она педантствует, беспрестанно окружена книгами, беспрерывно погружена в важные занятия» [9, с. 33]) или невежественной («считает Вольтера и Руссо, из которых не прочла ни строчки, “запустением мерзости”. Ум у нее нетронутый...» [6, с. 503]), добродетельной («Существуя преимущественно в возвышенной атмосфере искусства и свободы, поклоняясь всему великому, прекрасному и доброму, они понимают всякого, кто жертвует собой, и способны служить примером самой преданной дружбы» [Там же, с. 505]) или матерью внебрачного ребенка («Она, например, с ангельским терпением исполняет все капризы злобного сиротки, которого, если верить ей, она не оставляет своим попечением потому, что поклялась в этом его умирающей матери, и который так похож на нее саму, что все принимают ее за его бабку» [Там же, с. 511]), эгоистичной («она тайно бежала из родительского дома, вместо прощания оставив старому отцу, для которого она, единственная дочь, была последней радостью жизни и который тысячу раз умолял ее не покидать его, ибо он не переживет разлуки, записку» [Там же, с. 504]) или добросердечной («старая дева, обрекшая себя на труды и лишения всякого рода ради спасения разорившейся семьи или немощной матери» [Там же, с. 499]).

Как французская, так и русская старая дева может быть сестрой милосердия, ухаживать за больными («она облачается в монашеское одеяние сестры ордена Святого Венсана де Поля, посвящает себя служению бедным и немощным членам того самого общества...» [Там же, с. 506]; «Куда ни явится барышня, она везде нужна: там походит за больным... там о ней все вспомнили, потому что заболело дитя» [9, с. 36]). В сфере искусства как старая дева, так и барышня обычно откровенно бездарны: союз старой девы и инструмента вызывает у слушателей ужас [6, с. 503], а барышня может спеть только один «затверженный» романс. Религия играет особенно большую роль в жизни как французской, так и русской старой девы. Это отражается в ситуациях: старая дева может сбежать в монастырь [Там же, с. 504], может получить звание канониссы; барышня знает причет и священника, ласкова с ними, хорошо разбирается в обрядовой стороне церковных служб (где можно сесть, куда какую свечу ставить), часто и усердно молится («барышня усерднее помолилась Богу» [9, с. 37]).

Интересно, однако, что ученая старая дева различно описана в двух очерках: недоброжелательно (как педант, «беспрерывно погруженный в важные занятия» [Там же]) и насмешливо (с акцентом на то, что старой деве только и остается, что погрузиться в науку из-за невозможности выйти замуж [Там же, с. 33]) - в тексте русского автора - или же, как это делает Д’Эспийи, панегирически («достойная дочь Франции» [6, с. 505], «с благородным умом и пылом увлекающая учениц по пути прогресса» [Там же]). Кроме того, барышня, в отличие от французской старой девы, хорошо ладит с детьми («барышня проходит прямо в детскую... дети 
кидаются ей на шею с визгом» [9, с. 35]; «но это не помешает ей опять идти гулять с детьми; добрая барышня! Она их так любит» [Там же, с. 39]). Примечательно, что и в этой паре очерков упоминается имя барышни («А? Душа моя, Катерина Астафьевна!» [Там же, с. 36]) в русском тексте, в то время как во французском тексте старая дева остается безымянной, из-за чего образ барышни становится более индивидуализированным и привлекающим внимание читателя.

Авторы физиологических очерков для изображения незамужней девушки используют перефразированные цитаты из религиозных текстов либо отсылки к таковым. Так, например, Ж. Жанен, описывая жизнь до замужества богомолки в одноименном очерке (“La Dévote”, 1841), среди книг, которые читает героиня, упоминает знаковые тексты католицизма («Введение в благочестивую жизнь» св. Франциска Сальского, «Краткие великопостные проповеди» Жан-Батиста Массийона) и обращается к тексту Евангелия («Иго ее благо, бремя ее легко» (перефр. Матф. 11:30)) [7, с. 720]. Аналогичный прием используется и в рассматриваемых нами текстах: «...и считает Вольтера и Руссо, из которых не прочла ни строчки, “запустением мерзости”» (искаж. «мерзость запустения» (Матф. 24:15)) [6, с. 502]. Такая религиозность девы, впрочем, получает неоднозначную оценку со стороны окружающих. Во французском очерке девушка сбегает в монастырь, а ее отец скончался, не увидев из-за этого дочь перед смертью. Описание автором этого эгоистичного поступка невольно заставляет вспомнить осуждающие пассажи Льюиса о монастырях в «Монахе» (существует предположение, что подобная критика католицизма могла быть навеяна антиклерикальным théâtre monacal [3, с. 58]). Заканчивая ту часть очерка, в котором дается характеристика невежественности старой девы, Д’Эспийи иронически якобы цитирует ее духовника: «...она была, есть и будет белейшей из всех голубиц» [6, с. 503].

Конец жизни старой девы описывается одинаково пессимистично в обоих очерках: старая дева «умирает, как жила - в беспросветном одиночестве, и сходит в могилу, не оставляя о себе никакой памяти, кроме иногда - памяти о своем позоре» [Там же, с. 512]. Исчезновение барышни так прокомментировано княгиней, у которой барышня часто жила: «...та барышня, которая у меня гащивала? Право не знаю, что с нею... теперь гостит у меня другая» [9, с. 40].

\section{Заключение}

Делая выводы, отметим, во-первых, явную общность тенденции к детальному изображению общественных типов в русском и французском вариантах физиологического очерка, что возможно связать как с общим для европейского постромантического контекста интересом к «реальности», в том числе и в социальном ее проявлении, так и с популярностью французских образчиков жанра в России.

Во-вторых, стоит отметить некоторые не столь очевидные при поверхностном прочтении, однако оттого не менее важные признаки русского физиологического очерка, отличающие его от французского и выступающие знаками их принадлежности к отечественной традиции. Там, где французский очерк пользуется доставшимися в наследство от XVIII века (и риторической культуры в целом) сентименталистскими и сатирическими клише, русский очерк обнаруживает тенденцию к индивидуализации (имя собственное) протагониста, с одновременным символическим расширением на материале христианского предания (Пантелеимон). Тем самым выстраивается параллель к апологии «маленького человека» (Пушкин - Гоголь, ср. «Шинель» Гоголя 1842 г.) и (предвосхищающая) к христианизированным фигурам страдальцев и правдолюбов у Н. Лескова.

Перспективы дальнейшего исследования связаны с постановкой вопроса о прямом влиянии тех или иных французских очерков на русских авторов; разработка данного аспекта не входила в задачи настоящей статьи, но представляется важной и может стать основой для дальнейшего поиска.

\section{Список источников}

1. Башуцкий А. П. Водовоз // Наши, списанные с натуры русскими. СПб., 1841. Вып. 1-4. С. 1-29.

2. Белинский В. Г. Взгляд на русскую литературу 1847 г. // Белинский В. Г. Собрание сочинений: в 13-ти т. М.: АН СССР, 1956. Т. 10. С. 279-359.

3. Вацуро В. Э. Готический роман в России. М.: Новое литературное обозрение, 2002. 548 с.

4. Голубицкий Ю. А. Физиологический очерк как предтеча социологических исследований [Электронный ресурс]. URL: https://cyberleninka.ru/article/n/fiziologicheskiy-ocherk-kak-predtecha-sotsiologicheskih-issledovaniy (дата обращения: 18.12.2020).

5. Гусева Е. А. Становление и развитие физиологического очерка в русской литературе [Электронный ресурс]. URL: https://cyberleninka.ru/article/n/stanovlenie-i-razvitie-fiziologicheskogo-ocherka-v-russkoy-literature (дата обращения: 18.12.2020).

6. Д’Эспийи М. Старая дева // Французы, нарисованные ими самими. Парижанки / сост., вступ. ст. и ред. пер. В. Мильчиной. М.: Новое литературное обозрение, 2014. С. 495-512.

7. Жанен Ж. Богомолка // Французы, нарисованные ими самими. Парижанки / сост., вступ. ст. и ред. пер. В. Мильчиной. М.: Новое литературное обозрение, 2014. С. 713-738.

8. Карева Ю. А. «Литературный дебютант» А. Сегонда и «русский фельетонист» И. И. Панаева (французские физиологии на русской почве) [Электронный ресурc]. URL: https://elib.bsu.by/handle/123456789/56369 (дата обращения: 18.12.2020). 
9. Княжна -а. Барышня // Наши, списанные с натуры русскими. СПб., 1842. Вып. 5. С. 33-40.

10. Кулешов В. И. Натуральная школа в русской литературе XIX в. М.: Просвещение, 1982. 239 с.

11. Манн Ю. В. Философия и поэтика «натуральной школы» // Проблемы типологии русского реализма / под ред. Н. Л. Степанова и У. Р. Фохта. М.: Наука, 1969. С. 241-305.

12. Цейтлин А. Г. Становление реализма в русской литературе (русский физиологический очерк). М.: Наука, 1965. $321 \mathrm{c.}$

13. Шишмарева Е., Жуков Л. Физиологический очерк // Литературная энциклопедия: в 11-ти т. / ред. колл. П. И. Лебедев-Полянский, И. М. Нусинов; гл. ред. А. В. Луначарский; ученый секретарь Е. Н. Михайлова. М.: Худож. лит., 1939. Т. 11. Стб. 713-716.

14. Brisset M.-J. L’Ouvrier de Paris [Электронный ресурс] // Les Français peints par eux-mêmes. P., 1842. T. 1. URL: http://bergahammou.e-monsite.com/http-bergahammou-e-monsite-com-pages/les-francais-peints-par-euxmemes-encyclopedie-morale-du-dix-neuvieme-siecle/l-ouvrier-de-paris-mathurin-joseph-brisset-1792-1856.html (дата обращения: 18.12.2020).

15. Janin J. Le Gamin de Paris [Электронный ресурс] // Les Français peints par eux-mêmes. P., 1840. T. 1. URL: https:/www.gutenberg.org/files/60347/60347-h/60347-h.htm (дата обращения: 18.12.2020).

\section{Информация об авторах | Author information}

RU Петрова Римма Юрьевна ${ }^{1}$

${ }^{1}$ Санкт-Петербургский государственный университет

EN Petrova Rimma Yurievna ${ }^{1}$

${ }^{1}$ Saint-Petersburg State University

${ }^{1}$ rimma-petrova@mail.ru

\section{Информация о статье | About this article}

Дата поступления рукописи (received): 26.01.2021; опубликовано (published): 09.04.2021.

Ключевые слова (keywords): сравнительное литературоведение; физиологический очерк; тип; рецепция художественного текста в иноязычной среде; comparative literary studies; physiological essay; social type; literary text reception in foreign-language environment. 